\title{
ELECCIONES EN CHILE: ¿OTRA VEZ LO MISMO O AL REVES?
}

Rodrigo Baño

RESUMEN. Los resultados electorales, así como los sueños y una serie de acontecimientos menos volátiles que éstos, suelen prestarse para variadas interpretaciones, interpretaciones que, a menudo, son aún más ligeras que tales acontecimientos. En estos tiempos nadie puede tener la pretensión de lo eterno; por eso es que, en vez de apurarse a dar interpretaciones cuando los votos están aún calientes, quizás sea preferible llamar la atención acerca de ciertos hechos y aventurar probables cursos de acción si es que esos hechos tuvieran alguna importancia y si las condiciones no fueran alteradas. Poca cosa es lo que hacemos.

Al respecto se hace aquí un breve análisis de los principales resultados de las elecciones realizadas en Chile en 1989 en función de la discusión acerca de continuidades y cambios, para concluir acerca de posibles relaciones entre preferencias electorales y estratos sociales y las consecuencias que ello podría tener. A pesar de las dificultades que plantean al análisis muchas peculiaridades de esta primera elección, después de veinte años, es posible plantear algunas inquietudes sobre problemas de representación política.

\section{Introducción}

Los resultados electorales, así como los sueños y una serie de acontecimientos menos volátiles que éstos, suelen prestarse para variadas interpretaciones, interpretaciones que, a menudo, son aún más ligeras que tales acontecimientos. En estos tiempos, nadie puede tener la pretensión de lo eterno; por eso es que, en vez de apurarse a dat interpretaciones cuando los votos están aún calientes, quizás sea preferible llamar la atención acerca de ciertos hechos y aventurar probables cursos de acción, si es que esos hechos tuvieran alguna importancia y si las condiciones no fueran alteradas. Poca cosa es lo que hacemos.

\section{Reis}


El 14 de diciembre de 1989 se llevaron a cabo en Chile las elecciones generales para presidente de la República y diputados y senadores para el Congreso Nacional. Tales elecciones constituyen la culminación de un largo proceso de transición de régimen político, encaminado a poner fin a un prolongado período autoritario que duró más de dieciséis años. Las características de ese proceso de transición inciden muy directamente en el carácter de la elección y repercuten en sus resultados. Por tal razón, cualquier interpretación de resultados debe ser extremadamente prudente.

El autoritarismo militar impuesto tras el golpe de 1973 no sólo fue extraordinariamente represivo y violento, sino que impuso un modelo económico liberal que empezó a mostrar sus primeros frutos hacia 1980, circunstancia aprovechada por el régimen para hacer aprobar una Constitución política y la reelección del general Pinochet como jefe de Estado. Todo ello, naturalmente, sin las más mínimas garantías de un proceso electoral medianamente correcto.

La crisis económica iniciada en 1982 gatilla la protesta social y pone en jaque al Gobierno. Sin embargo, la división social y política de la oposición permiten que el régimen logre controlar la situación mediante una serie de maniobras y concesiones socialmente focalizadas. Todo ello en la espera de la recuperación económica, que empieza a producirse en 1985.

La división social se percibe claramente entre sectores populares y capas medias, en la medida que estas últimas se sienten amenazadas por la fuerte movilización popular, especialmente manifestada en las "protestas" en las poblaciones pobres. Frente a ello, las capas medias se descuelgan de esas protestas, que inicialmente habían apoyado, dejando así aislados a los sectores populares, que son duramente reprimidos.

La división política se manifiesta en la existencia de dos coaliciones partidarias independientes, una encabezada por la Democracia Cristiana y otra por el Partido Comunista. Estas no sólo tienen la obvia diferencia de su orientación política, sino que en su objetivo común de derrocar al régimen autoritario difieren en sus métodos y en la base social donde buscan su principal apoyo. Esta división implica, naturalmente, muy distintas alternativas de resolución del conflicto en torno al régimen político.

Ya es conocida la derrota de la estrategia insurreccional, que se hace explícita en 1986 con el fracaso del atentado al general Pinochet y el previo descubrimiento de los arsenales escondidos en el Norte. Desde ahí la dirección de la oposición la toma firmemente la Democracia Cristiana, atrayendo cada vez más fuertemente a su estrategia a partidos de izquier$\mathrm{da}$, con la exclusión rotunda del Partido Comunista y grupos afines.

Establecida la salida institucional del conflicto, la oposición logra garantías de limpieza del plebiscito sobre continuidad del general Pinochet, y lo derrota electoralmente el 5 de octubre de 1988. Siguiendo los 
pasos del itinerario constitucional, dada esa situación, procede la realización, en un año más, de elecciones generales de presidente de la República y de representantes al Congreso. A partir de aquí cede grandemente el clima confrontacional, hasta el punto de que se logra un acuerdo entre el Gobierno, los partidos de derecha que lo apoyan y la oposición para hacer algunas reformas constitucionales que eliminaran ciertos rasgos excesivamente autoritarios, a la vez que legitimaban la vigencia constitucional. Todo ello ratificado en un rápido y consensual plebiscito. En ese clima se llegó a las elecciones generales.

Hay que señalar, también, que si bien la fuerza de la movilización opositora y de factores internos entre los sectores dominantes lograron impulsar la transición, ésta se hizo dentro de la normatividad dictada por el régimen autoritario. En lo que se refiere más directamente a las elecciones generales, hay dos leyes que tienen una importancia muy grande en el carácter de éstas. Se trata de la ley de partidos políticos y la ley electoral.

La ley de partidos consagraba, de acuerdo con la Constitución, la prohibición de formar partidos de inspiración marxista, los que tradicionalmente fueron los partidos de la izquierda chilena. Esto obligó a que esos partidos, una vez aceptada la transición institucional, se inscribieran bajo otros nombres como colectividades más amplias. Así se presentó el Partido Por la Democracia (PPD), agrupando principalmente a los socialistas moderados, y el Partido Amplio de Izquierda Socialista (PAIS), agrupando principalmente a comunistas y socialistas ortodoxos.

Por su parte, la ley electoral, orientada a favorecer a los partidos del Gobierno, estableció un extraño sistema “binomial». Según él, se elegían dos diputados por distrito y dos senadores por circunscripción y ganaban las listas que tuvieran las dos primeras mayorías. Sólo si una lista doblaba en votos a la que le seguía podía obtener los dos representantes. Esto significaba que bastaba tener un poco más de un tercio para obtener la mitad del Parlamento. Esto estaba diseñado para forzar un sistema bipartidista y, en todo caso, asegurar a las fuerzas conservadoras que apoyaron el régimen militar una nutrida representación parlamentaria, aunque fueran minoría. En los hechos, esto forzó a la formación de dos grandes coalicio:nes políticas: una de derecha (Renovación Nacional-UDI) y una de centro-izquierda (DC, PPD, socialistas y otros partidos menores). El Partido Comunista, excluido por la DC de la alianza de centro-izquierda, tuvo que ir en lista aparte, acompañado en algunos casos por el PS (Almeyda), el MIR y otros grupos menores de izquierda.

Por cierto que es conveniente recordar tanto las circunstancias en que se dan estas elecciones generales como las condiciones que imponía la institucionalidad vigente para analizar los resultados producidos. 
No es del caso relatar aquí las discusiones y anécdotas que se produjeron en el proceso de selección de candidatos. Basta señalar lo que parece más relevante para el caso. Esto es, por una parte, que la selección del candidato de la oposición al régimen militar resultó relativamente fácil, dado que siempre se le reconoció a la DC el "mejor derecho" para nominarlo y que la conducción de la victoriosa campaña sobre el plebiscito le aseguraban a Patricio Aylwin un capital político importante.

Por otra parte, la selección del candidato de la derecha resultó extremadamente difícil. Se mezclaban ahí, conflictivamente, tanto los intereses del Gobierno por proyectar su continuidad como los de la derecha política por su constitución como partido para participar con éxito en el juego democrático. A la vez, había una abierta desconfianza del sector empresarial hacia esa derecha que pretendía representarlo, añorando los tiempos en que los militares se hicieron cargo del asunto. Finalmente, el sector empresarial impuso al ex ministro de Hacienda del general Pinochet, Hernán Büchi.

Por último, el empresario de independiente derecha, Francisco Javier Errázuriz, mantuvo su candidatura, alentado por aquellos partidarios del régimen militar que creían que arrastraría suficientes votos como para impedir que Aylwin garara en la primera vuelta. Sus recursos en la campaña fueron, sin embargo, muy pocos. Carente de una organización política, sólo pudo utilizar sus propios medios económicos de empresario exitoso.

A pesar de que, como ya señalamos, el clima confrontacional se había suavizado ostensiblemente desde el plebiscito, puede decirse que las candidaturas presentadas reproducían de alguna manera la alternativa régimen militar-oposición que ocupaba el eje principal del conflicto durante largos años. La salida del general Pinochet del primer plano era reemplazada por la de su ex ministro de Hacienda. Con ello se pretendía simbolizar la continuidad de un modelo económico considerado como exitoso, a la vez que se evitaba representar el carácter autoritario y represivo de un régimen político que se daba ya por superado. Particularmente desde que las fuerzas armadas optaron por garantizar la salida del general Pinochet, permitiendo que éste fuera derrotado, al apoyar la existencia de garantías de un proceso electoral correcto e imponer el respeto a sus resultados.

Por su parte, todas las fuerzas políticas que hicieron la oposición al régimen militar, cualesquiera que hayan sido sus tácticas y objetivos finales, aparecían apoyando a quien era el presidente del principal partido opositor.

Los resultados de la elección presidencial no constituyeron una sorpresa para nadie. Lo cierto es que ni los más fervientes partidarios del Gobierno apostaban por un triunfo de Büchi. Sólo los más audaces se 
atrevían a especular sobre la posibilidad de que Aylwin no lograra mayoría absoluta en la primera vuelta.

El triunfo de Aylwin, aunque no espectacular, resultó cómodo (véase cuadro 1). Prácticamente repitió el porcentaje que en el plebiscito obtuvo el NO a la reelección de Pinochet. Sin embargo, y aunque parezca raro, la derrota de Büchi fue aplastante, ni siquiera alcanzó al 30 por 100 de los votos. Lógicamente, tal situación sólo pudo producirse por la excelente que obtuvo Francisco Javier Errázuriz. Y decimos excelente votación por el hecho de que la obtuvo sin organización partidaria, sin grandes recursos y en una situación que se sabía bastante polarizada entre defensores y contrarios al régimen del general Pinochet.

\section{CUADRO 1}

Resultado elección presidencial

(Votos válidamente emitidos)

\begin{tabular}{|c|c|}
\hline & $\%$ \\
\hline 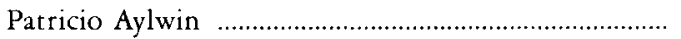 & 55,17 \\
\hline 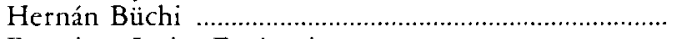 & 29,40 \\
\hline 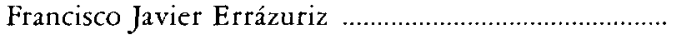 & 15,43 \\
\hline
\end{tabular}

Estos resultados son bastante claros en cuanto constituyen un claro triunfo de quienes fueron opositores al régimen militar, y que se presentaban como los más decididos partidarios de impulsar la transición a la democracia, realizando las transformaciones necesarias para que ella se imponga en plenitud en breve tiempo.

Definida la elección presidencial en torno al eje autoritarismo-democracia, el triunfo es para esta última opción y para la coalición de centroizquierda que la impulsó. Sin embargo, los problemas surgen cuando se trata de medir la fuerza que presenta la alternativa derrotada. Esta dificultad arranca de dos tipos de problemas. El primero es la confusión que se produce entre el régimen militar y la derecha política; el otro se refiere a la evaluación del significado de la candidatura de Francisco Javier Errázuriz.

En cuanto a la confusión entre régimen militar y derecha política, habría que señalar que ella se inicia a partir del golpe militar de 1973, cuando el partido de derecha (Partido Nacional en ese entonces) se autodisuelve proclamando que se sienten plenamente representados por el régimen militar. Sus personeros políticos apoyan durante largos años al régimen del general Pinochet, y sólo muy tarde, cuando se empieza a rear- 
mar el sistema de partidos bajo el impulso de la movilización social, comienzan a rearticularse como organizaciones políticas. El proceso de independización del régimen es lento y con continuos retrocesos. Finalmente optan por la independencia, pero manteniendo lazos con el Gobierno y tratando de proyectarse como continuadores de lo bueno del régimen militar (la economía) pero críticos de lo malo (autoritarismo y excesos represivos).

Esta confusión entre régimen militar y derecha plantea ciertos inconvenientes para evaluar los resultados. Es así, por ejemplo, cómo es ostensible que Renovación Nacional apoyó muy tibiamente a Hernán Büchi, mientras que la UDI lo impulsó casi como su hombre. Difícil es saber lo que Büchi representaba para la población como hombre de derecha o como expresión del régimen del general Pinochet.

Por su parte, si bien Errázuriz es un empresario que hace una campaña de corte populista de derecha, tampoco es sencillo calificarlo simplemente como parte de la derecha política.

En consecuencia, si bien la elección presidencial aclara cuál es el apoyo que tiene la agrupación de fuerzas de centro e izquierda, no aclara cuál es la que tiene la derecha ni cuál es el respaldo que aún tenía el régimen militar. Como veremos más adelante, el simple expediente de sumar los votos de Büchi y Errázuriz para compararlos con los de Aylwin, para sostener que se repitió la votación del plebiscito de 1988, no parece adecuado.

\section{Las elecciones parlamentarias}

A diferencia de las presidenciales, las elecciones parlamentarias estuvieron mucho más orientadas a la competencia partidaria entre diversas opiniones. Estas elecciones correspondían a un anhelo largamente perseguido por los partidos, en cuanto a buscar las bases para orientarse a la constitución de fuertes organizaciones políticas. En cierto sentido se presentaba como la primera medición de fuerzas después del largo período de exclusión de actividad partidaria.

Sin embargo, esta medición de fuerzas resulta bastante imperfecta debido a las circunstancias que hemos mencionado al comienzo, y especialmente a la legislación sobre partidos políticos y sistema electoral, que limitaba enormemente la competencia partidaria.

En efecto, dicha legislación excluyó la posibilidad de participación directa de partidos de izquierda y, a la vez, al rechazar la representación proporcional e implantar un extraño sistema binominal, forzó a la formación de coaliciones para evitar la pérdida de votos.

Según lo esperado, los dos grandes pactos electorales que se presentaron acapararon casi totalmente los cargos en disputa. Sólo la lista G, Uni- 
dad para la Democracia, formada por los comunistas y algunos socialistas, logró obtener dos diputados. Los demás, con excepción de un independiente, se los adjudicaron el pacto Concertación por la Democracia (70) y el pacto Democracia y Progreso (48). Además, estas dos listas principales se adjudicaron la totalidad de los senadores (véase cuadro 2).

\section{CUADRO 2}

Parlamentarios elegidos por pacto electoral

\begin{tabular}{|c|c|c|}
\hline & Diputados & Senadores \\
\hline $\begin{array}{c}\text { Concertación por la Democracia (DC, PPD, PS, PR y } \\
\text { otros) }\end{array}$ & 70 & 22 \\
\hline 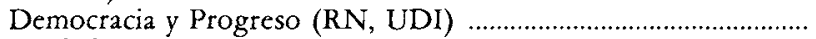 & 48 & 16 \\
\hline Unidad para la Democracia (PC, PS, IC, PRSD, MIR) ................... & 2 & 0 \\
\hline 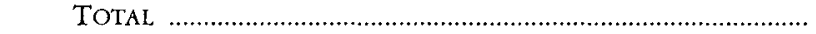 & 120 & 38 \\
\hline
\end{tabular}

En términos de votación, los dos pactos mayoritarios logran controlar gran parte de la votación, qudando sólo poco más del 10 por 100 para repartirse entre la lista encabezada por los comunistas, listas de pequeños partidos de derecha y algunas listas de independientes (véase cuadro 3).

\section{CUADRO 3}

\section{Elecciones parlamentarias}

(Porcentaje total de votos por pacto electoral)

\begin{tabular}{|c|c|c|}
\hline & Diputicias & Senudores \\
\hline Concertación por la Democracia & 51,48 & 54,63 \\
\hline 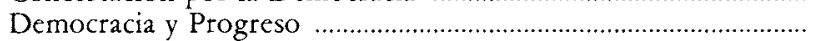 & 34,18 & 34,85 \\
\hline 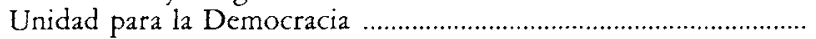 & 5,31 & 4,24 \\
\hline Otros pactos . & 9,03 & 6,28 \\
\hline TOTAL & 100,00 & 100,00 \\
\hline
\end{tabular}

No obstante, hay ciertas dificultades menores para calcular el peso total de cada uno de los grandes pactos, dado que los pactos pequeños se presentaban sólo en algunas regiones y distritos. Esto puede tener cierta importancia en cuanto a los partidos de oposición al régimen militar, ya 
que la izquierda iba tanto en el pacto de Concertación como en el formado por comunistas y socialistas ortodoxos. Así, cuando no iba este último pacto no se sabe cuántos votos de la izquierda iban a la Concertación, aunque un sector de ella no pertenecía formalmente al pacto.

Sea como sea, la proporción de votos obtenidos por las dos grandes coaliciones es considerable y explica que prácticamente lograran la casi totalidad de los cargos en disputa.

Pero cuando se requiere ir más allá del cálculo de los totales obtenidos por las coaliciones y se pretende estimar la fuerza electoral de cada partido, el asunto se torna especialmente complicado.

Mal que mal, la configuración de las listas electorales predefine quiénes pueden ser elegidos. Dado que sólo pueden ir dos candidatos por lista en cada región o distrito y que se tiene una estimación (de acuerdo al plebiscito) sobre en cuáles se tiene más o menos ventajas, la elección se decide más en la mesa de negociación de los partidos que en la votación popular. De aquí que en cada coalición las elecciones, más que una medición de fuerzas ante la ciudadanía, sean una consecuencia de la fuerza que se reconocen u otorgan entre sí los distintos partidos políticos. Es de acuerdo a esto último como se cuotean las candidaturas que posteriormente recibirán la votación pertinente.

Incluso el cálculo de cuál es el respaldo que en estas circunstancias recibe cada partido resulta difícil, dado que, salvo los partidos más grandes, que son los que hacen de cabeza de las dos principales coaliciones, generalmente cada uno sólo lleva candidatos en algunos pocos lugares.

A pesar de todos estos problemas, que es necesario tener en cuenta, se puede hacer una estimación del porcentaje de votación que apoya a ciertos partidos, especialmente en el caso de los que encabezan los pactos. Al respecto sólo se pueden indicar porcentajes aproximados (véase cuadro 4).

\section{CUADRO 4}

\section{Estimación aproximada de votación} de principales fuerzas políticas

\begin{tabular}{|c|c|}
\hline & $\%$ \\
\hline Democracia Cristiana & 34 \\
\hline Renovación Nacional - UDI .. & 34 \\
\hline Izquierda (PPD, PS, PC y otros) & 22 \\
\hline Partidos menores de derecha & 5 \\
\hline 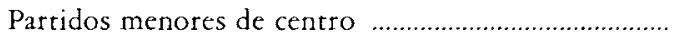 & 5 \\
\hline
\end{tabular}


En la derecha el cálculo resulta aún más difícil, debido al hecho de que se incluyeron en la lista una gran cantidad de candidatos independientes, los cuales, en general, son personajes que estuvieron ligados al gobierno del general Pinochet, especialmente como alcaldes e intendentes. En todo caso, llama la atención el hecho de que en los distritos en que compitieron para diputados candidatos de Renovación Nacional y de la UDI, éstos obtuvieron en promedio porcentajes muy similares. El que Renovación Nacional haya obtenido más del doble de diputados que la UDI puede deberse en buena medida a que en la negociación del pacto impuso y obtuvo el reconocimiento al "mejor derecho" de presentar más candidatos. De hecho, Renovación Nacional presentó 81 candidatos y la UDI sólo 34 en los 60 distritos.

En la lista de la Concertación por la Democracia se puede estimar la votación de la Democracia Cristiana en aproximadamente 33 por 100, lo cual deja para la izquierda y partidos menores de centro un 27 por 100 .

Ahora bien, hilar más fino en estos cálculos resulta prácticamente imposible. Existe la impresión de que la izquierda moderada recibe mayor respaldo que aquella más extrema, pero eso no se puede comprobar, dado el hecho de que evitaron cuidadosamente competir. Los mejores resultados que obtiene la izquierda moderada, que se presenta bajo el PPD, corresponden a su situación privilegiada en el pacto de la Concertación, sin que pueda saberse si eso también significa un efectivo respaldo electoral.

Si se comparan los resultados de la elección parlamentaria con los de la presidencial se tienen datos interesantes (véase cuadro 5). Existen diferencias importantes entre la votación obtenida por los candidatos presidenciales y la de las coaliciones y fuerzas políticas que los apoyaron. Aylwin obtiene 4 por 100 menos que los partidos que lo apoyan, mientras que Büchi logra 6 por 100 menos que su base partidaria. En cambio, Errázuriz conquista 10 por 100 más de la votación que puede estimarse para los pequeños partidos de derecha que lo apoyaron.

\section{CUADRO 5}

Comparación votación presidencial

y parlamentaria

\begin{tabular}{|c|c|c|}
\hline & Presidencial & $\begin{array}{c}\text { Parlamentaria } \\
\text { (senadores) }\end{array}$ \\
\hline 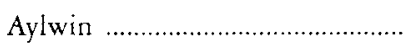 & 55,17 & 59,27 \\
\hline Büchi & 29,40 & 34,85 \\
\hline 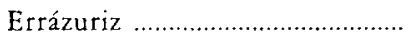 & 15,43 & 6,28 \\
\hline
\end{tabular}


Estas diferencias no son desdeñables y pueden aportar bastante en la búsqueda de una interpretación de los resultados, aunque, evidentemente, hay muchos otros factores en juego.

\section{Las altemativas de interpretación planteadas}

Dado lo reciente de las elecciones generales chilenas, no existen todavía estudios serios sobre sus resultados. Sin embargo, entre políticos e intelectuales se suelen plantear dos enfoques sobre ellos, enfoques que plantean prácticamente las alternativas lógicas que tendría su comparación con el sistema de preferencias partidarias previo al golpe militar de 1973. Es decir, si ha surgido un nuevo cuadro político o si ha reaparecido el antiguo sistema de fuerzas políticas.

Entendemos aquí como el antiguo sistema de fuerzas políticas aquel vigente desde la segunda mitad de la década de los cincuenta, a lo menos, sin entrar en la discusión de si tal sistema reconoce mayor antigüedad. En líneas generales, ese sistema se presentaba encuadrado en tres tendencias relativamente equilibradas: la izquierda, el centro y la derecha, que se reconocían como tales y que se diferenciaban según límites bastante nítidos. Tal sistema es conocido comúnmente como de "los tres tercios", por el peso equivalente que tenía la división tripartita. Además, parte de la responsabilidad por la crisis institucional que desembocó en el golpe militar se atribuye a este sistema de tres tercios, que hacía que, normalmente, se eligiera presidente con un tercio y se tuviera inmediatamente una oposición mayoritaria que se atrincheraba en el Parlamento.

La cuestión, simplemente planteda, en relación con los recientes resultados electorales, es si se mantiene o cambia ese esquema nítido de tres tercios.

\section{Acerca del posible nuevo cuadro político}

La perspectiva de la formación de un nuevo cuadro partidario se desarrolla primariamente desde el mismo gobierno del general Pinochet y es asumido muy pronto por la derecha política.

El régimen militar, cuando ya se hace insostenible su posición antipartido, tiende a inclinarse claramente por un sistema bipartidista, tratando de impulsar a través de la legislación la formación de dos grandes partidos que le dieran estabilidad al sistema político. El primer proyecto de ley de partidos establecía un muy alto número de adherentes, justamente para evitar la proliferación de partidos, pero luego tuvo que ceder para incentivar a los partidos opositores a meterse en la institucionalidad. Mejor suerte tuvo con la ley electoral que comentamos anteriormente, la cual sólo 
por una apresurada reforma permitió la existencia de pactos políticos y que en los hechos obliga a la agrupación de fuerzas políticas en dos bloques. Es una ley electoral directamente diseñada para el bipartidismo.

Por su parte, los partidos de derecha bien pronto adoptaron el eslogan gobiernista de que las organizaciones políticas se dividen entre las que son "partidarias de una sociedad libre" y las "estatistas". Reiteradamente han declarado obsoletas las diferenciaciones entre izquierda, centro y derecha. En la práctica, insisten porfiadamente en autodenominarse partidos de "centro-derecha", lo que implícitamente los opone a alguna "centroizquierda».

Sin embargo, tal perspectiva no sólo corresponde a la derecha, sino que en otras tendencias políticas también se habla de cambio en el cuadro político, aunque no hay tanta atracción por el bipartidismo. Es así como en el Partido Por la Democracia se desarrolló una fuerte discusión interna en cuanto a la definición de su posición en el eje, habiendo un sector de él que se manifestó explícitamente por declararlo de centro político, no obstante haber sido una creación electoral del ala moderada del socialismo chileno. En todo caso, la tendencia prevaleciente es a diferenciar dos izquierdas y dos derechas, aunque la jibarización de los extremos y el acercamiento de la izquierda y la derecha moderadas al centro vuelve a plantear, a futuro, las posibilidades de un bipartidismo.

Sea como sea, lo cierto es que los resultados electorales recientes parecen admitir la interpretación de que se habría producido un nuevo cuadro político.

Tal interpretación arranca del hecho de que la elección apareció gruesamente planteada a dos bandas: el gobierno y la derecha, por un lado, y el centro y la izquierda, por el otro. Esto resultó particularmente notorio en la confección de los pactos electorales, al surgir dos grandes pactos que representaban, con exclusión de los extremos, a los que habían sido partidarios del SI o del NO en el plebiscito de 1988 sobre continuidad del general Pinochet como jefe de Estado.

Respecto a la elección presidencial se señala que Aylwin en la práctica repitió la votación que obtuvo en el plebiscito, mientras que los dos candidatos de derecha suman el porcentaje que recibió el SI (véase cuadro 6).

\section{CUADRO 6}

Comparación elección presidencial con plebiscito de 1988

Plebiscito 1988

Elección presidencial
NO $\quad 56 \% \quad$ SI

$44 \%$

Büchi

Aylwin $\quad 55 \%$

Errázuriz 
A la vez, el alto porcentaje de votos recibidos por las listas parlamentarias de derecha estaría revelando que ya no se podría hablar de los famosos tres tercios.

Según esta perspectiva, se había producido un nuevo alineamiento electoral en términos de dos bloques. La votación obtenida por la derecha no sería espurea, sino firme y con posibilidades de aumentar en el futuro si hace una inteligente oposición al nuevo gobierno. Esto plantearía competencia entre esos dos bloques en el mediano plazo. A la vez, los distintos partidos podrían pasar a competir dentro de cada bloque para obtener su dirección o, al menos, mejorar posiciones.

Esta interpretación de los resultados tiene a su favor la simplicidad del análisis y su vinculación con la forma en que efectivamente se presentan las fuerzas políticas al iniciarse el nuevo gobierno democrático. Su debilidad está en la escasa consideración de las condiciones concretas en que se da el proceso electoral y en una visión unilateral del significado de la candidatura de Errázuriz.

Respecto a las condiciones en que se produce el proceso electoral, nos remitimos a lo ya dicho y que aconseja mayor prudencia en la interpretación. Por otra parte, aunque pareciera que el temor no ha incidido mayormente en apoyar candidatos gobiernistas, siempre es necesario tener en cuenta el factor control del poder y lo que eso puede significar en cada caso concreto. Tenemos, además, la fuerte tendencia a la moderación propia de transiciones de este tipo y la circunstancia extraordinaria de que el régimen militar concluye mostrando un éxito económico que no encuentra parangón en América Latina y que, naturalmente, constituye la base de propaganda de sus partidarios.

En cuanto al significado de la candidatura de Errázuriz, que logra un elevado 15 por 100 de la votación, creemos que es difícil atribuirla a la derecha sin más. Como se sabe, su tono fue fuertemente populista. Aun cuando pueda catalogarse de populismo de derecha, no es lo mismo que la derecha en cuanto a respaldo electoral. Más aún, su mantención como candidatura pareció obedecer a la estrategia de que, si bien le quitaba votos a Büchi, también le quitaba a Aylwin, lo cual podría posibilitar una segunda vuelta.

Esta situación se demostraría en el hecho de que Aylwin obtiene menos votos de los que obtienen los partidos que lo apoyan en las parlamentarias (véase cuadro 5). Esto es particularmente claro en las elecciones de senadores, de manera que se puede proyectar que la votación que obtuvo Errázuriz provino en dos tercios de potenciales partidarios de Büchi y en un tercio de potenciales partidarios de Aylwin.

En el caso de los diputados hay que hacer notar que, alinque la votación de los partidos que apoyaron a Aylwin es siempre superior a la obtenida por éste, hay una ligera merma que se produce precisamente debido a 
la fuerte votación que logran ex alcaldes del régimen en sus distritos. Factor éste que también debe tomarse en cuenta.

Por todo esto podría decirse que la buena votación obtenida por Errázuriz, así como la alcanzada en algunos distritos por ex alcaldes, está respondiendo a un fenómeno distinto que al realineamiento de fuerzas er dos bloques.

No debe confundirse el que los partidos se hayan visto obligados a presentarse en dos bloques con el hecho de que las fuerzas políticas se organicen de aquí en adelante de esa forma. Tampoco la alta votación de la derecha es necesariamente constante, sino que más parecce deberse a factores circunstanciales.

\section{Acerca del resurgimiento del esquema partidario tradicional}

La otra línea de interpretación es, lógicamente, la inversa. Esto ès, se plantea que no se produce cambio en las fuerzas políticas, sino que, al concluir su prescripción, éstas reaparecen como estaban antes del golpe militar. El principio de "congelamiento del sistema partidario", una vez alcanzado cierto nivel de desarrollo, se mantendría a pesar de la larga interrupción autoritaria.

El primer argumento en favor de esta línea de interpretación arranca del hecho de que los partidos que emergen durante el autoritarismo, y que llevan a cabo la larga campaña destinada a acabar con él, son, naturalmente, aquellos que existían previamente. Los partidos de derecha, aunque tardíamente, se rearticulan también a partir de sus tradiciones y, aunque lentamente, comienzan a autonomizarse del gobierno.

Se admite que habría partidos importantes con nuevos nombres, pero ellos corresponderían básicamente a tendencias preexistentes. Sería el caso de Renovación Nacional, que desplaza al Partido Nacional, y el Partido Por la Democracia (PPD), que agrupa a los sectores más moderados del socialismo y que tendería a desaparecer en el Partido Socialista, que se ha vuelto a unificar.

Cuando se analizan los resultados electorales desde esta perspectiva, el análisis tiende a ser muchísimo más sofisticado, ya que, como hemos visto, en las elecciones parlamentarias no hay competencia partidaria entre partidos del mismo bloque.

De acuerdo a tales análisis se llega, un poco más o un poco menos, según la tendencia del analista, a considerar algunas estimaciones aproximadas como las expuestas en el cuadro 4. Esto sirve para afirmar que la división en las tres principales tendencias prevalece y que, con ciertas consideraciones, se puede decir que permanece algo aquello de los tres tercios. La derecha con un tercio grande (cercano al 40 por 100), el centro o 
Democracia Cristiana con su tercio exacto (33 por 100) y la izquierda con su tercio disminuido (22-25 por 100$)$.

La derecha se plantearía a dos bandas, con su sector mayoritario representado en Renovación Nacional y su sector extremo independizado en la UDI. El centro seguiría básicamente en la Democracia Cristiana.

La izquierda, con más problemas, se rearticularía en un unificado Partido Socialista, siendo más difícil la situación de los comunistas, que no salen de sus crisis, permanecen marginados y obtuvieron una pobre votación que no les permitió ni un solo parlamentario en la lista autónoma de izquierda que se vieron obligados a formar.

En esta visión "continuista" del sistema partidario se pone especial énfasis en las circunstancias muy particulares que rodearon el último evento electoral y se espera que, al irse normalizando el proceso democrático, se vaya haciendo más clara esa continuidad del sistema. Explícitamente se considera que la derecha tiene que desinflarse en forma relativamente rápida al desaparecer las circunstáncias que la favorecieron, en especial el temor al caos y el manejo de los recursos de poder que tenían en el régimen anterior.

En cuanto a la elección presidencial, esta interpretación no se ocupa mucho de ella, por tratarse de un caso extremo de coaliciones obligadas en el que no se sabe cuánto aporta cada cual ni lo que se gana o pierde por la unidad misma. Además, la votación de Errázuriz se presta para todo tipo de especulaciones.

Así, someramente bosquejada, esta interpretación no resulta enteramente convincente. De hecho, requeriría mucha mayor elaboración y, ciertamente, es difícil que alguien la exponga en los términos más categóricos. Pero, en lo esencial, constituye una interpretación plausible y por eso la presentamos.

El problema es que, dadas las características de la elección, es sumamente difícil calcular el peso real de los partidos. Pero ése no es el único problema. Quizás lo más importante sea el surgimiento de fuerzas políticas nuevas que reciben fuerte respaldo electoral.

Tal es el caso en la derecha de Renovación Nacional, que se define de centro-derecha no sólo por razones de propaganda, sino que busca efectivamente una aproximación al centro para mejorar su imagen y posibilidades de éxito.

En la izquierda se da la situación del PPD, que se ubica exactamente igual que Renovación Nacional, pero desde este otro costado. No basta señalar que el PPD desaparecerá ante el reunificado Partido Socialista. Mal que mal, no hay aún seguridad de que el PPD desaparezca y, aun si así ocurriera, también es posible que la orientación del PPD se traslade al Partido Socialista.

Por último, habría que señalar la delicada situación del Partido Comu- 
nista, cuya participación en la izquierda tradicional ha sido esencial y de cuyo destino es bien poco lo que se puede aventurar.

En resumen, las interpretaciones acerca de la continuidad del esquema partidario vigente antes del golpe militar requieren una cantidad de matices, precisiones y alcances que, si se exageran, pueden llegar a desvirtuar la idea misma de continuidad.

\section{El fantasma social en la política}

El esquema más usado en las exposiciones consiste en presentar dos posiciones antagónicas extremas para concluir en una solución ecléctica del problema. Naturalmente que no se puede discutir los atractivos que tendría una hipótesis ecléctica respecto del sistema partidario en Chile después del régimen militar. Bastaría señalar que no es que todo cambie o permanezca, sino que algunas cosas cambian y otras permanecen. Quizás esto hasta tenga algo de cierto. Pero lo que nos interesa señalar aquí, finalmente, son ciertas consideraciones que podrían incidir bastante en la determinación de qué es lo que cambia y qué es lo que permanece.

Al respecto, nos parece pertinente preocuparnos de un aspecto que consideramos bastante central en la determinación de un sistema de partidos. Nos referimos a la cuestión de la relación que puede establecerse entre los partidos y sectores sociales definibles en términos socioeconómicos.

En Chile, hasta 1973, existía una cierta tradición de representación política de lo social que era comúnmente admitida. Hay, incluso, algunas investigaciones al respecto que establecen la existencia de estas relaciones. Aquellos estudios que han pretendido demostrar lo contrario suelen refutar relaciones muy estrictas, que por cierto no las hay, y los datos aportados no logran desvirtuar la existencia de tales relaciones.

De acuerdo a eso, y en términos genéricos y aproximados, podría decirse que la derecha representaba a los sectores empresariales, el centro a las capas intermedias y la izquierda a los sectores populares. Insistimos, tomado esto como tendencia amplia; afirmar que existían relaciones estrictas sería, naturalmente, una aberración.

Ahora bien, como hemos señalado en múltiples oportunidades, a partir de la década de los ochenta, y especialmente a medida que avanzaba la transición a la democracia, ha existido una clara tendencia a cambiar esta situación. Esto se plantea fundamentalmente en términos de umodernización» política, tendente a eliminar un rasgo que se ha considerado pernicioso en los partidos políticos, especialmente de izquierda, esto es, la "ideologización" y el intento de representación de sectores sociales específicos. El modelo de sustitución propuesto es el partido de programa (que 
desplaza al ideológico), de votantes y no de militantes, de convocatoria nacional y no sectorial, de marketing y no de concientización.

Aunque todas estas características no necesitan ir juntas, de hecho se presentan así y, en el punto que nos preocupa aquí, se insertan en esa tendencia a romper con la tradición de representación política de lo social. Situación que creemos es extraordinariamente compleja en el caso de los sectores populares. No en vano es entre ellos donde nace la noción moderna de partido político para defender sus intereses frente al poder general.

Si nos abocamos a los resultados electorales, veremos que ellos no son ajenos a aquellas divisiones sociales básicas. Divisiones que, simplificadamente, las podemos ver en cuanto al corte existente en los estratos socioeconómicos. Tal ejercicio se puede hacer en Chile debido a la muy fuerte segregación espacial existente entre sectores de altos y bajos ingresos.

De acuerdo a un análisis muy somero, es posible sostener que siempre existió una clara diferenciación social en el apoyo o rechazo al régimen militar. Así lo mostró abundantemente la movilización social en su contra. Para demostrar que esto no era simplemente cuestión de activistas, tenemos los resultados electorales tanto del plebiscito de 1988 como de las elecciones presidenciales de 1989.

En ambos casos encontramos claros indicios de que los sectores de más altos ingresos apoyan al general Pinochet y a Büchi, mientras que las poblaciones pobres rechazan al general Pinochet y eligen a Aylwin (véase cuadro 7). Esto algo significa en términos de alineación izquierda-derecha, pues no se puede dejar de recordar que el general Pinochet derrocó a un gobierno de izquierda para instaurar un largo reinado de la derecha, aunque $\sin$ expresiones partidarias.

\section{CUADRO 7}

Comparación votación en el plebiscito y presidencial entre comunas más ricas y más pobres de Santiago

Quinta Normal

Cerro Navia

Lo Prado

\begin{tabular}{cc} 
& Elección \\
Plebiscito & presidencial \\
NO & Ayluin \\
\hline
\end{tabular}

61,3

65,0

64,8

12,0

10.5

34,7
58,8

66,2

67,3

37.5

36.0

29.7 
Por las razones que hemos señalado reiteradas veces, resulta prácticamente imposible determinar el peso electoral efectivo que tiene cada partido dentro de los pactos, puesto que normalmente no hay competencia abierta. No obstante lo anterior, resulta sintomático que en los distritos más pobres, en los principales centros urbanos (Santiago, Valparaíso y Concepción), la izquierda haya sacado una proporción de votos muy superior a la media nacional estimada. Esto se produce tanto en la votación de candidatos de izquierda que van en la lista de la Concertación como en los que van en la lista autónoma de la izquierda dura. De la misma manera, se aprecia un alza en la votación de la derecha en aquellos distritos más ricos. La comparación del distrito 18 (pobre) con el distrito 25 (rico) es ilustrativa al respecto (véase cuadro 8 ).

\section{CUADRO 8}

Comparación distrito 18 (pobre) con distrito 23 (rico) en elección de diputados

\begin{tabular}{|c|c|c|}
\hline & \multicolumn{2}{|c|}{ PORCENTAJES } \\
\hline & Distrito 18 & Distrito 23 \\
\hline 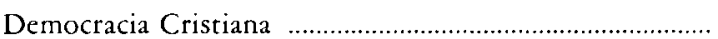 & 30,0 & 26,1 \\
\hline Los Verdes & 3,9 & - \\
\hline Total centro & 33,9 & 26,1 \\
\hline Renovación Nacional & 12,9 & 41,5 \\
\hline UDI & 11,0 & 19,0 \\
\hline Otros derecha & 9,0 & 2,6 \\
\hline Total derecha ............... & 32,9 & 63,1 \\
\hline 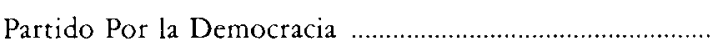 & - & 8,5 \\
\hline Partido Comunista & 15,7 & - \\
\hline MIR (1) & 6,9 & - \\
\hline Total izquierda & 22,6 & 8,5 \\
\hline
\end{tabular}

De acuerdo a un examen somero de las cifras, es posible especular que aún se mantiene una cierta relación de sectores sociales con tendencias políticas, en el sentido lato de afinidad de los sectores de mayor ingreso con la derecha y de sectores de menor ingreso con la izquierda. Sin embargo, por decirlo a la antigua, resulta muy nítido que los sectores altos tienen una más fuerte "conciencia de clase" que los populares. En estos últimos la tendencia es más débil. 
Ahora bien, parte de esa debilidad se explica por la atracción que ejerce en esos sectores un cierto "populismo de derecha". En efecto, puede resultar de mucha importancia observar que en esos sectores reciben un buen respaldo tanto la candidatura de Francisco Javier Errázuriz como la de candidatos de la UDI que fueron ex alcaldes en el respectivo distrito.

Frente a este tipo de antecedentes es posible pensar que la llamada "modernización" política, en cuanto ella signifique una desvinculación de los partidos políticos de reales o supuestas representaciones sociales, no pareciera ocurrir con facilidad. Tal vez esta sociedad chilena no sea tan moderna como algunos piensan, pues siguen habiendo, tanto en la derecha como en la izquierda, ciertas afinidades sociales.

En el caso de la izquierda, el debilitamiento de las afinidades sociales pareciera beneficiar más a posiciones de corte clientelístico o populista que a opciones de tipo racional programáticas.

Puestas así las cosas, es posible hipotetizar que en el futuro de mediano plazo se dan dos alternativas. Una es que la izquierda asuma y se le reconozca su carácter de representación política de los sectores populares. La otra es que, no existiendo una representación política partidaria de estos sectores, ellos deriven hacia el atractivo de opciones clientelísticas y populistas que, eventualmente, pueden echar por tierra las expectativas de estabilidad política.

Por cierto que siempre encontraremos situaciones intermedias y confusas más que el desarrollo de alternativas típicas. En todo caso, tal vez convenga hacer notar que aún pareciera tener algo que ver lo político con lo social. En consecuencia, las especulaciones respecto de la continuidad o cambio del sistema de partidos podrían tomar en consideración antecedentes de esta especie. 